\title{
Transmigration route of Campylobacter jejuni across polarized intestinal epithelial cells: paracellular, transcellular or both?
}

\author{
Steffen Backert ${ }^{1 *}$, Manja Boehm ${ }^{1}$, Silja Wessler ${ }^{2}$ and Nicole Tegtmeyer ${ }^{1}$
}

\begin{abstract}
Intact intercellular junctions and cellular matrix contacts are crucial structural components for the formation and maintenance of epithelial barrier functions in humans to control the commensal flora and protect against intruding microbes. Campylobacter jejuni is one of the most important zoonotic pathogens causing food-borne gastroenteritis and potentially more severe diseases such as reactive arthritis or Guillain-Barré syndrome. Crossing the intestinal epithelial barrier and host cell invasion by $C$. jejuni are considered to represent the primary reasons of gut tissue damage in humans and various animal model systems including monkeys, piglets, rabbits, hamsters and ferrets. C. jejuni is also able to invade underlying tissues such as the lamina propria, can enter the bloodstream, and possibly reach distinct organs such as spleen, liver or mesenteric lymph nodes. However, the molecular mechanisms as well as major bacterial and host cell factors involved in these activities are poorly understood. Various models exist by which the pathogen can trigger its own transmigration across polarized intestinal epithelial cells in vitro, the paracellular and/or transcellular mechanism. Recent studies suggest that bacterial factors such as flagellum, serine protease HtrA and lipooligosaccharide LOS may play an active role in bacterial transmigration. Here we review our knowledge on transmigration of $C$. jejuni as well as some other Campylobacter species, and discuss the pros and cons for the route(s) taken to travel across polarized epithelial cell monolayers. These studies provide fresh insights into the infection strategies employed by this important pathogen.
\end{abstract}

Keywords: Adherens junctions, Cell polarity, E-cadherin, Fibronectin, HtrA, Integrins, Invasion, Molecular pathogenesis, Cellular invasion, Signaling, TER, Tight junctions, Transmigration, Virulence

\section{Introduction}

Campylobacter jejuni is a wide-spread Gram-negative bacterium living as commensal in the gut of most birds and domestic animals. However, C. jejuni is infectious for humans and consumption of contaminated food products is a major cause of human bacterial gastroenteritis, which may be responsible for as many as 400-500 million cases annually [1]. The clinical outcome of $C$. jejuni infection varies from mild, non-inflammatory, self-limiting diarrhoea to severe, inflammatory, bloody diarrhoea that can continue for few weeks [2-5]. In some cases, $C$. jejuni infections can be also associated with the development of reactive arthritis and peripheral neuropathies, known

\footnotetext{
* Correspondence: Steffen.Backert@fau.de

'Department of Biology, Institute for Microbiology, Friedrich Alexander University Erlangen/Nuremberg, Staudtstr. 5, D-91058, Erlangen, Germany Full list of author information is available at the end of the article
}

as Miller-Fisher and Guillain-Barrè syndromes [6,7]. Despite the significant health burden caused by $C$. jejuni infections, our present knowledge about the interplay between $C$. jejuni and its various hosts is still very limited. The availability of complete genome sequences from various $C$. jejuni isolates has started to improve our understanding in genetics, physiology, pathogenesis and immunity of $C$. jejuni infections in recent years. $C$. jejuni is the first bacterium reported to encode for both $\mathrm{O}$ - and $\mathrm{N}$-linked glycosylation systems, a property that is likely influencing the host-pathogen crosstalk and disease outcome. In addition, a multitude of infection studies in various animal and in vitro cell model systems revealed the importance of $C$. jejuni motility and chemotaxis as critical features important for establishing successful infections [2,8-10]. In particular, the high motility $\left(\mathrm{Mot}^{+}\right)$permits C. jejuni to effectively move to its favored colonization 
niche at the inner mucus layer of the human intestine. Various in vivo and in vitro studies have shown that this pathogen encodes numerous virulence determinants involved in important disease-associated processes such as bacterial adhesion to, transmigration across, invasion into and intracellular survival within infected intestinal epithelial cells [11]. In the present article we review our current knowledge including various recent developments in C. jejuni research on how this bacterium can breach the gut epithelial barrier and transmigrate across polarised cell layers. In particular, we focus on the two major known routes that could be taken, the transcellular and paracellular ways of $C$. jejuni transmigration. Better molecular understanding of these pathways and the identification of involved bacterial and host factors is crucial for the future development of effective treatment regimes.

\section{The intestinal mucosa is a first barrier against microbial infections}

The intestinal mucosal epithelium in humans is an important cell layer that controls not only digestive, absorptive and secretory functions, but also forms the first barrier against pathogenic microbes [12]. The intact structure of healthy intestinal epithelial cells is maintained by the integrity of the apical-basal polarity, forming microvilli structures with a well-defined brush border, a highly organized actin-cytoskeleton and proper junctional complexes [13,14]. Importantly, well-established junctions are built up on the lateral cell-to-cell contacts including tight junctions (TJs) and E-cadherin-based adherens junctions (AJs) as well as basally located integrin-mediated cell-matrix contacts such as focal adhesions (FAs) and hemidesmosomes (HDs). While FAs are present both in cultured polarised and non-polarised cells, TJs, AJs, and HDs are only established in polarised and absent in non-polarised epithelial cells (Figure 1A,B). A model for the overall protein composition of these junction complexes is shown in Figure 2.

TJs are based on junction adhesion molecules (JAMs), claudins, occludin and other proteins, which represent important structural elements in establishing epithelial cell polarity. They are crucial for the tight sealing of the cellular sheets, thus controlling paracellular ion flux and therefore maintaining tissue homeostasis. The tight apposition of the membranes at TJs, which are localized at the apical end of the lateral membrane, also blocks lateral mobility of membrane proteins and lipids allowing the segregation of membrane components in an apical and basolateral compartment (Figures $1 \mathrm{~B}$ and $2 \mathrm{~A}$ ). The $\mathrm{AJs}$ are positioned basal to TJs and form a network of membrane proteins and associated molecules, which are responsible for the mechanical adhesion between neighboring cells (Figures 1B and 2B). AJs assemble via homophilic, calciumdependent interactions between the extracellular domains of E-cadherin on the surface of two adjacent epithelial cells. E-cadherin does not only act as an adhesive protein, but also has important functions as a regulator of cell proliferation. By modulating the availability of $\beta$-catenin, which binds to the intracellular domain of E-cadherin and helps to connect AJs with the actin cytoskeleton, E-cadherinbased AJs are involved in cell signaling and transcriptional regulation. Therefore, disturbed E-cadherin signaling is also associated with tumorigenesis [15]. The FAs comprise the third group of cell adhesion structures and consist of integrin heterodimers (composed of $\alpha$ and $\beta$ chains), which are transmembrane receptors that link the extracellular matrix to intracellular FA proteins (Figures $1 \mathrm{~B}$ and $2 \mathrm{C}$ ). FAs modulate multiple signaling cascades to regulate cell attachment, proliferation, migration, differentiation and gene expression events. These processes are controlled by classical 'outside in' and 'inside out' signal transduction pathways $[16,17]$. The extracellular domain of a given integrin can directly bind to extracellular matrix proteins such as fibronectin, while the cytoplasmic tail is linked to the actin-cytoskeleton via a large number of adapter proteins, including vinculin, paxillin or talin, and signaling enzymes such as focal adhesion kinase (FAK) or Src kinase (Figure 2C). These protein complexes continually assemble and disassemble, and this turnover process must be differentially controlled at the leading edge versus the trailing edge of a migrating cell. In addition, HDs constitute adhesive protein complexes that mediate stable attachment of basal epithelial cells to the underlying tissues [18]. Similar to FAs, the organization of HDs relies on a complex network of protein-protein interactions, but in HDs integrin $\alpha 6 \beta 4$, laminin and plectin play essential roles (Figures $1 \mathrm{~B}$ and $2 \mathrm{D}$ ). Interestingly, many microbial pathogens including $C$. jejuni have adapted mechanisms during evolution to exploit TJs, AJs, FAs and/or HDs in infected cells in order to proliferate, survive and sometimes persist within the host [12,19-21].

\section{Detection of $C$. jejuni in the intestinal mucus, lamina propria, blood and other organs during infection in vivo} A major goal of current $C$. jejuni research is to define the exact role of bacterial adhesion, invasion and transmigration across enterocytes for the induction or absence of pathogenesis in different hosts. Several in vivo studies of human biopsies and infected animal models reported on observations of $C$. jejuni entering gut epithelial cells and underlying subepithelial tissues during infection (Table 1). For example, electron microscopic studies of biopsies from patients with campylobacteriosis have shown that $C$. jejuni can closely associate to the surface or within the intestinal epithelium, especially in Goblet cells, and was focally present in the lamina propria [22]. The majority of patients exhibited the histological picture of acute infectious colitis associated with massive infiltration of immune cells and 
A

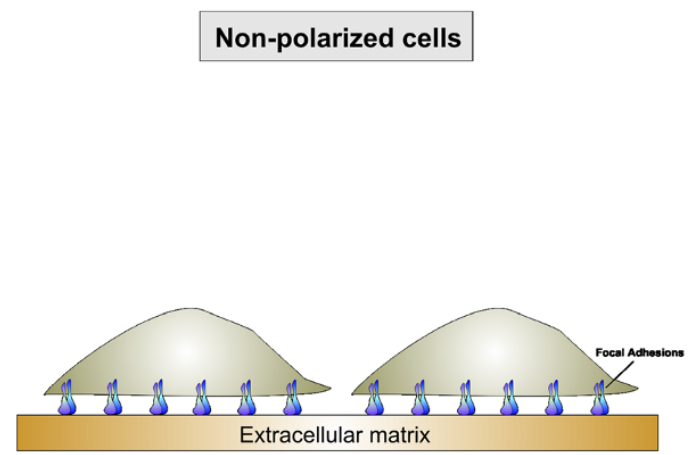

C

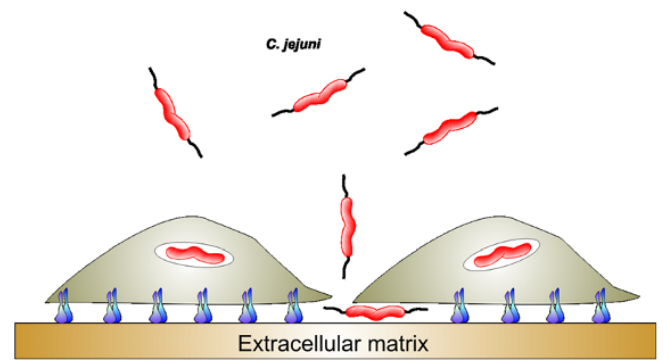

B

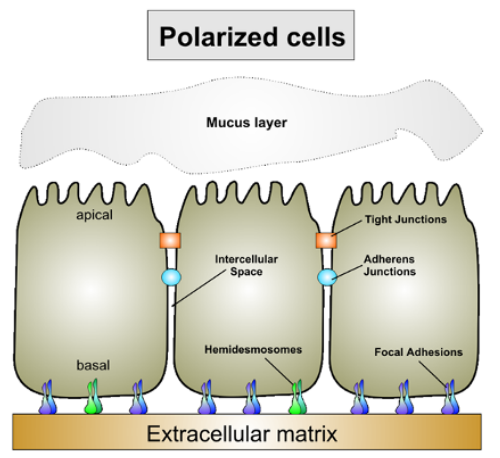

D

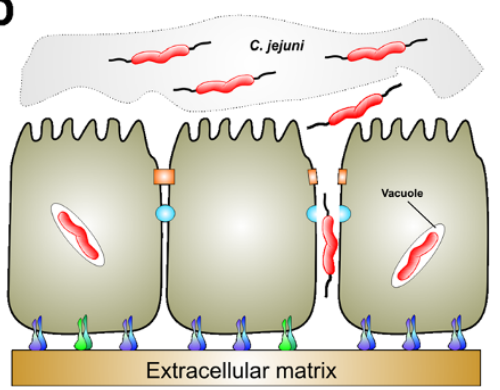

Figure 1 A schematic presentation of non-polarised and polarized intestinal cell epithelial cells under non-infective conditions or during infection with C. jejuni. (A) Cultured non-polarised intestinal epithelial cells such as INT-407 do not express typical cell-to cell junctions. Thus, basolateral receptors such as focal adhesion structures are accessible and not protected by tight or adherens junctions. (B) Polarised intestinal epithelial cells such as mucin-producing HT29-MTX-E12 cells express the different types of intercellular junctions including the tight junctions (orange), adherens junctions (light blue), focal adhesions (dark blue) and hemidesmosomes (green) which exhibit specific localization in the lateral or basal membranes as indicated. GAP junctions and desmosomes are other examples which are not discussed in this review article. (C,D) C. jejuni is able to infect both cell variants in vitro. This pathogen encodes numerous described pathogenicity-associated factors involved in important processes including bacterial adhesion to, transmigration across, invasion into and intracellular survival within intestinal epithelial cells. For more details see text.

marked distortion of crypt architecture. Penetration of $C$. jejuni into the intestinal tissue is also supported by the presence of blood and leukocytes in stool samples. Similar observations were obtained during C. jejuni infection experiments in monkeys [23], hamsters [24], piglets [25], rabbits [26] and ferrets [27]. In addition, live $C$. jejuni were recovered from other organs in infected animals such as the spleen [28-30], liver [27,29,30], mesenteric lymph nodes [29] and blood [26]. This suggests that $C$. jejuni exhibits the capability not only to adhere to and enter into enterocytes, but can also travel within the host, pass the intestinal epithelial barrier, enter the lamina propria and even access other organs of various infected hosts. Interestingly, a mixed set of results were obtained from infection experiments in chicken and mice. In multiple studies $C$. jejuni was regularly seen attached to or within colonic epithelial cells, lamina propria and other organs of chicken and mice [28-31]. However, C. jejuni infection resulted either in no obvious pathology or in less pathology as compared to humans or the above discussed other animal model systems (Table 1). In contrast, in some other reports C. jejuni was not seen attached to or inside intestinal epithelial cells, although high loads of bacteria were noted in the corresponding extracellular mucus layer [32,33]. These studies suggest that adhesion of $C$. jejuni to and invasion into intestinal epithelial tissues occurs in vivo, but may vary substantially in various chicken and mouse model systems, probably depending on the $C$. jejuni strain, variant and age of animals and other infection parameters (Table 1).

What is the advantage for $C$. jejuni to cross the epithelial barrier and infect underlying tissues?

The degree by which a given pathogen can translocate through an epithelial cell barrier and the bacterium's fate beyond the local environment differs substantially between different known microbes. For example, Salmonella typhi rapidly translocates across a polarized monolayer, causing cellular disruption leading to a complete loss of cell monolayer integrity. In contrast, the transcytosis of Salmonella typhimurium across polarized cells results in minimal damage to the epithelial monolayer [34,35]. Presumably these observations reflect disease manifestation in vivo, 


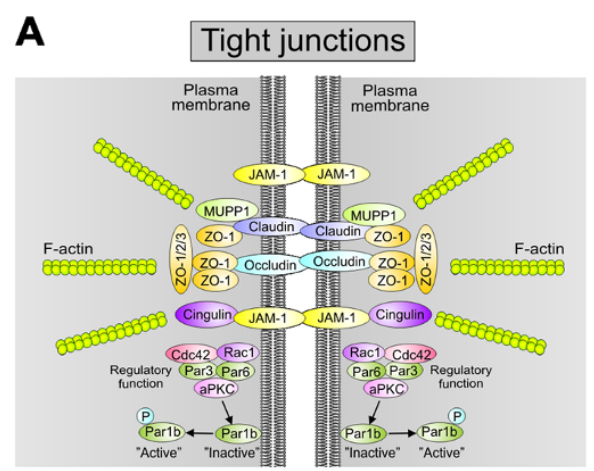

C

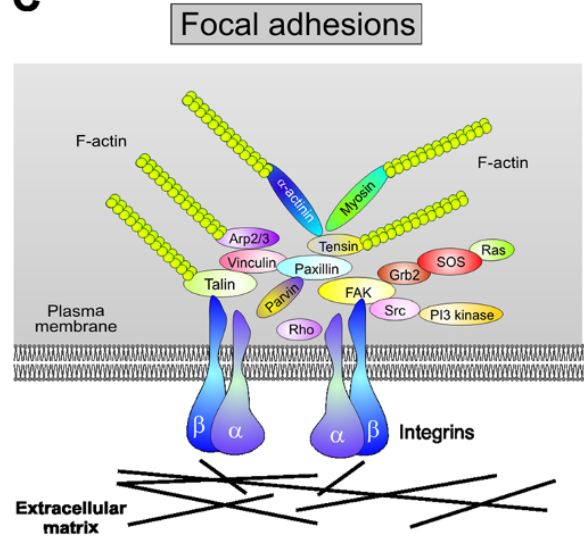

\section{B Adherens junctions}

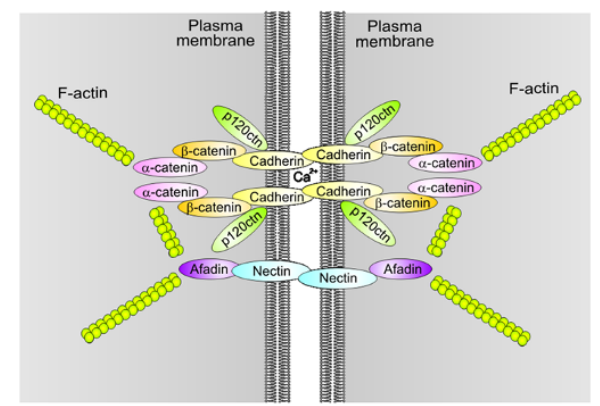

D

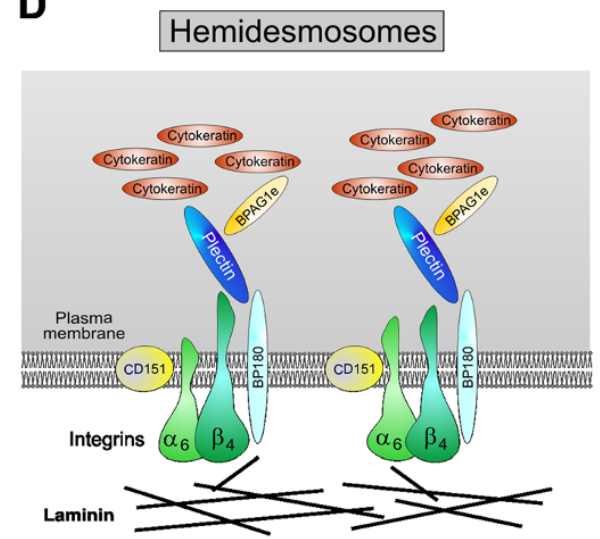

Figure 2 Composition of major intercellular junctions in the polarized intestinal epithelium. Schematic presentation of specific junctional complexes and associated signaling pathways. (A) Tight junctions (TJs) contain at least four major groups of transmembrane proteins: the JAMs, claudins, occludin and a number of cytoplasmic peripheral proteins. While the transmembrane proteins mediate cell-to-cell adhesion, the cytosolic TJ complex connects to different factors (e.g. ZO-1/-2/-3, MUPP1 or cingulin) that link the involved transmembrane proteins to the actin-cytoskeleton. The integrity of TJs is maintained by a regulatory complex including atypical PKC (aPKC), Rac1, Cdc42, Par6 and Par3. (B) The calcium-dependent integrity of adherens junctions (AJs) is stabilized by binding of E-cadherin to the intracellular catenins. The carboxy-terminal domain of E-cadherin binds to the cytoplasmic protein $\beta$-catenin. p120-catenin binds to the juxtamembrane part of E-cadherin and stabilizes the AJ complex. The E-cadherin- $\beta$-catenin structure is connected to the actin-cytoskeleton via binding to a-catenin and Eplin. When the E-cadherin complex is disrupted, $\beta$-catenin can translocate into the nucleus and activate Tcf/LEF transcription factors. (C) Focal adhesions (FAs) are structural complexes that link the extracellular matrix (ECM) to the intracellular actin-cytoskeleton. They contain various integrin heterodimers which are transmembrane receptors composed of $a$ and $\beta$ chains. The extracellular integrin tail directly binds to ECM proteins such as fibronectin, while the cytoplasmic domain is linked to the actin-cytoskeleton via a large number of indicated adapter/signaling proteins to transmit signaling. (D) Hemidesmosomes are also located at the basal side of epithelial cells where they link laminins to the intracellular intermediate filament network. Thus, hemidesmosomes provide stable adhesion of epithelial cell layers to the basement tissue. They consist of integrin a6ß4, CD151 and BP180 which are transmembrane proteins, while plectin and BPAGle are located in the cytoplasm. Plectin mediates linkage of hemidesmosomes to the cytokeratin network and not to F-actin filaments.

where infections with S. typhi are commonly septic in patients whereas infections with S. typhimurium are commonly restricted to the intestinal mucosa. By comparison to Salmonella, infections with C. jejuni are usually less acute. Advantages for $C$. jejuni reaching the underlying tissues and submucosa include that the bacteria are no longer subject to peristaltic forces in the intestine and they may gain pronounced access to certain nutrients such as iron. In addition, invasive $C$. jejuni can achieve contact with a set of basal host cell receptors such as fibronectin, which are normally not present at apical surfaces. Another advantage could be that the intracellular environment is better protected to antibiotics as compared to the gut lumen. Finally, by causing inflammatory diarrhea in the intestine, $C$. jejuni can improve its own spread to find a new host. This is in agreement with observations that stools from patients are diarrheal and remain C. jejunipositive for several weeks [2-5].

\section{Use of non-polarised and polarised cells to study C. jejuni infection in vitro}

Among others, the C. jejuni isolates 81-176, NCTC11168, F38011 and 81116 are the most commonly used strains in laboratories for infection studies in vitro (Table 2). Infection 
Abbreviations: ASC (antibody-secreting cells); CFU (colony forming units); CFU-D (CFU determination); Cj (Campylobacter jejuni); CVM (crypt-vilus measurements); ELISA (enzyme linked immunosorbent assay); $E R$

(immung

microscopy); TEM (transmission electron microscopy); TNF-alpha (tumour necrosis factor alpha). 
Table 2 In vitro studies of $C$. jejuni translocation across polarized epithelial cell lines using transwell assays ${ }^{\mathrm{a}}$

\begin{tabular}{|c|c|c|c|c|c|c|c|c|c|c|}
\hline $\begin{array}{l}\text { Applied } \\
\text { cell model }\end{array}$ & $\begin{array}{l}\text { Time of cell } \\
\text { differentiation/ } \\
\text { growth }\end{array}$ & $\begin{array}{l}\text { Confirmation } \\
\text { of proper TJs } \\
\text { before infection }\end{array}$ & $\begin{array}{l}\text { C. jejuni } \\
\text { strains used }\end{array}$ & $\begin{array}{l}\text { Negative } \\
\text { controls used }\end{array}$ & $\begin{array}{l}\text { Applied methods } \\
\text { to investigate } \\
\text { transmigration }\end{array}$ & $\begin{array}{l}\text { C. jejuni } \\
\text { factors } \\
\text { involved }\end{array}$ & $\begin{array}{l}\text { Host factors } \\
\text { involved }\end{array}$ & $\begin{array}{l}\text { Proposed } \\
\text { transmigration } \\
\text { route }\end{array}$ & $\begin{array}{l}\text { TER values during } \\
\text { transmigration }\end{array}$ & References \\
\hline Caco-2 & 10-14 days & TER (300-500) & $\begin{array}{l}\text { 78-27, 81116, M129, } \\
\text { F38011 }\end{array}$ & E. coli DH5a & TWA, TER, PIS, SEM, TEM & NP & NP & $\begin{array}{l}\text { Paracellular and } \\
\text { transcellular }\end{array}$ & Unchanged (within 6 h) & {$[40]$} \\
\hline Caco-2 & NP & NP & 37 clinical isolates & E. coli DH5a & TWA, CAA, GPA, CTA & NP & NP & Paracellular & NP & [36] \\
\hline Caco-2 & 10-14 days & NP & 81116 & E. coli DH5a & TWA, TER, CAA, GPA, IB & $\mathrm{FlaA} / \mathrm{B}$ & NP & NP & Unchanged (5 h) & {$[37]$} \\
\hline Caco-2 & 10-14 days & TER (250) & 6 clinical isolates & E. coli DH5a & TWA, TER, CPT & NP & NP & $\begin{array}{l}\text { Paracellular and } \\
\text { transcellular }\end{array}$ & $\begin{array}{l}\text { Small drop of TER } \\
\text { (from } 250 \text { to } 200 \text { ), } \\
\text { but loss after } 24 \mathrm{~h}\end{array}$ & [49] \\
\hline Caco-2 & 7 days & TER (430) & 10 clinical isolates & NP & TWA, TER, CAA, GPA & NP & NP & $\begin{array}{l}\text { Paracellular and } \\
\text { transcellular }\end{array}$ & $\begin{array}{l}\text { Changes were strain } \\
\text { dependent }(6 \mathrm{~h})\end{array}$ & [38] \\
\hline T84 & NP & NP & $81-176$, F38011 & E. coli MRF & TWA, CAA, GPA & NP & NP & Paracellular & NP & [42] \\
\hline Caco-2 & 7 days & TER $(>1000)$ & 81-176, NCTC11168 & NP & TWA, SEM, TEM, GPA & NP & NP & $\begin{array}{l}\text { Paracellular and } \\
\text { transcellular }\end{array}$ & NP & [39] \\
\hline HCA-7, T84 & 8-10 days & TER (400-550) & 19 clinical isolates & NP & $\begin{array}{l}\text { TWA, GPA, TEM, LDH, } \\
\text { MF, IL-8, PGE2 }\end{array}$ & NP & NP & Paracellular & Unchanged (12 h) & {$[50]$} \\
\hline Caco-2 & 17 days & TER (1056) & R27456 & E. coli DH5a & TWA, GPA, EPA, PIS & NP & NP & Transcellular & Unchanged (48 h) & [84] \\
\hline T84, MDCK-I & NP & TER (400-500) & $\begin{array}{l}\text { NCTC11168, } \\
81-176, \text { TGH9011 }\end{array}$ & NP & TWA, PIS, GPA, EPA, TEM & $\mathrm{FlgF}$ & PI3-K & Transcellular & $\begin{array}{l}\text { Unchanged }(24 \mathrm{~h}) \text {, } \\
\text { drop after } 48 \mathrm{~h}\end{array}$ & [43] \\
\hline T84 & NP & TER (values NP) & $81-176$, CHR213 & E. coli HB101 & TWA, PIS, IFM & $\mathrm{FlaA} / \mathrm{B}$ & $\begin{array}{l}\text { Cholesterol, } \\
\text { caveolin }\end{array}$ & Transcellular & Unchanged (4 h) & {$[85]$} \\
\hline MKN-28 & 14 days & TER (130-150) & $81-176$, NCTC11168 & E. coli DH5a & TWA, TER, CA, ECA, IB & HtrA & E-cadherin & Paracellular & Unchanged (24 h) & {$[44,45]$} \\
\hline Caco-2 & 19 days & TER (values NP) & GB11, GB19 & NP & TWA, IFM, GPA & Cst-II & NP & Transcellular & NP & [59] \\
\hline
\end{tabular}

${ }^{a}$ Abbreviations: CAA (cell adhesion assay), CA (casein assay); CPT (cell permeability test using ${ }^{14} \mathrm{C}$-Inulin labelling); Cst-II (sialyltransferase); CTA (cytotoxic activity assay); ECA (E-cadherin cleavage assays), EPA (epithelial permeability assay); FlaA/B (flagellin genes A and B); FlgF (flagellar gene F); GPA (gentamicin protection assay); MF ( ${ }^{3} \mathrm{H}$ ] mannitol flux); IFM (immunofluorescence microscopy); HtrA (high temperature resistant protein $\mathrm{A}$ a serine protease); IB (immunoblotting ); IL-8 (IL-8 measurement); LDH (lactate dehydrogenase test); NP (not provided in the study); PGE2 (prostaglandin E2 measurement by ELISA); PI3-K (phosphoinositid-3-kinase); PIS (pharmacological inhibitor studies); SEM (scanning electron microscopy); TEM (transmission electron microscopy); TER (transepithlial electrical resistance measurement, values given in Ohms per $\mathrm{cm}^{2}$ ); $T J$ (tight junction); TWA (transwell assay). 
experiments of cultured cell lines with $C$. jejuni have shown that the bacteria can bind to $\left(\mathrm{Bind}^{+}\right)$, invade into $\left(\mathrm{Inv}^{+}\right)$ and survive inside a defined intracellular compartment $\left(\right.$ Surv $\left.^{+}\right)$, called the Campylobacter-containing vacuole. These phenotypes, have been reported for both $C$. jejuni infection of non-polarised and polarised epithelial cells (Figure 1C,D). Studies of the translocation capabilities of $C$. jejuni strains across an intestinal epithelium in vitro require tight polarized cell monolayers. Typical chosen cell lines expressing TJs, AJs and FAs include Caco-2 [36-40], T84 [41-43], MDCK-I [43] or MKN-28 [44,45]. In addition, some of the polarised epithelial cell lines such as HT29MTX-E12 have been shown to produce a mucus layer and thus maybe also very useful as they could better mimic the natural environment in the intestine $[46,47]$. It has been described that while $C$. jejuni can adhere to different cell lines with similar extend, the bacterial invasion and transmigration capacities can vary considerably between the different cell lines [43,48-50]. It was proposed that $C$. jejuni can enter cultured epithelial cell lines of human origin with higher efficacy as compared to non-human cells, suggesting that the pathogen is particularly specialised for diseasetriggering infection of the human host [48].

\section{Bacterial and host factors with proposed roles in C. jejuni adhesion and invasion of intestinal cells}

Although the exact molecular mechanisms triggering adhesion of $C$. jejuni to intestinal epithelial cells are still not fully understood, several studies have provided evidence in recent years that this is a multifactorial process requiring the concerted activity of various $C$. jejuni factors, which are under much debate $[2,11,51]$. Application of the gentamycin protection assay (GPA) and other approaches led to reports of more than 20 bacterial gene products potentially mediating the interaction of $C$. jejuni with various host cell lines. These factors comprise numerous genes of the flagellar apparatus [52-56], pseA modifying flagellin with the acetamidino form of pseudaminic acid [57], lipooligosaccharide (LOS) biosynthesis gene galE [58], sialyltransferase cst-II gene [59], N-glycosylation genes $p g l B$ and $p g l E$ [60], capsule biosynthesis genes kpsM and kpsE [61,62], autotransporter CapA [63], Peb1-4 membrane proteins [64-67], serine protease HtrA [45,68,69] and the fibronectin-binding proteins CadF and FlpA [70-73]. In addition, the proposed lipoprotein Cj0497 [74], cytochrome c oxidoreductase SOR encoded by the genes cj0004c and cj0005c [75], CJIE1 prophage homologs [76], components of a type VI secretion system (T6SS) [77] and surfaceexposed lipoprotein JlpA [78] have also been shown to influence $C$. jejuni host cell adhesion. However, it is not yet clear if all above factors contribute directly or indirectly to $C$. jejuni-mediated host cell binding. Another handicap is that some described adherence factors cannot be confirmed by other groups [11]. For example, JlpA is dispensable for the binding of $C$. jejuni to chicken-derived hepatocellular epithelial carcinoma cells [73]. However, mutagenesis of most of these adhesion-related factors also exhibited distinct defects in invasion of $C$. jejuni suggesting a possible positive correlation between bacterial adhesion and host entry events. One interesting exception is again the $j l p A$ mutant. This mutant exhibits a reduced adherence phenotype by $\sim 20 \%$ of wild-type level [78], but was not defective for host cell entry $[73,79,80]$. Taken together, while a considerable number of putative bacterial binding factors have been described for $C$. jejuni, there is a large gap in our knowledge on the corresponding host cell receptors.

\section{C. jejuni transmigration across polarised epithelial cells in transwell chambers: role of protein biosynthesis and temperature}

Different well-known intestinal pathogens such as Listeria, Shigella, Salmonella or Yersinia have the capability to transmigrate across the gut epithelial barrier (Trans ${ }^{+}$strains), gain access to deeper tissues, trigger cell damage and cause disease in humans. There are two general mechanisms how bacterial pathogens can overcome the epithelial barrier, described as the paracellular and the transcellular migration routes [34,35]. Pathogens utilising the paracellular mechanism break the TJ and AJ complexes and cross the epithelial barrier by passage between neighboring epithelial cells [12]. In contrast, some other pathogens specialised on the transcellular mechanism and invade epithelial or specialised $M$ cells at the apical surface followed by intracellular trafficking and exit these cells at the basolateral membrane $[81,82]$. Studies on the translocation capabilities of $C$. jejuni across an intestinal epithelium layer in vitro have been performed with multiple strains and polarized cell lines grown in transwell chambers (Table 2). Migration of various Trans ${ }^{+}$C. jejuni strains from the apical compartment of transwells through polarized cells was confirmed by determination of colony forming units (CFU) obtained from the lower chamber, GPA and other functional assays. Application of chloramphenicol, a well-known inhibitor of bacterial protein biosynthesis, reduced the transmigration potential of C. jejuni significantly [40]. The failure of chloramphenicol to completely abolish translocation may indicate that some of the bacteria possess the factors necessary to facilitate penetration while others may have to synthesize such components de novo [40]. C. jejuni adherence, penetration and transmigration activities were also inhibited at lower temperatures when investigated at $20^{\circ} \mathrm{C}$ and $4^{\circ} \mathrm{C}$ as compared to $37^{\circ} \mathrm{C}$ [40]. These data suggest that adhesion, internalization and translocation of $C$. jejuni require active bacterial and host cell processes at optimal temperature. The current, common opinion is that $C$. jejuni can effectively transmigrate in vivo and in vitro, but the involved mechanisms (paracellular and/or transcellular) 
are controversial in the literature (Table 2) and will be discussed below.

\section{Role of the chosen polarised cell line and variability among wild-type $C$. jejuni strains}

Most of the polarised cell lines applied to study $C$. jejuni transmigration were of human origin (Caco-2, HCA-7, T84 and MKN-28). The majority of utilised $C$. jejuni strains can markedly interact with these cells and actively transmigrate in large quantities within 1-6 h, while a negative control (non-pathogenic Escherichia coli) did not (Table 2). One of the most popular and well-investigated cell lines is Caco-2, and invasive wild-type C. jejuni strains such as 81-176, NCTC11168, F38011 and 81116 also revealed pronounced capabilities to transmigrate across polarised Caco-2 cells and represent typical $\mathrm{Inv}^{+} / \mathrm{Trans}^{+}$isolates (Table 2). Based on these criteria, however, it is not possible to decide if the strains transmigrate either by the paracellular or transcellular pathway, respectively. $\mathrm{Inv}^{+} / \mathrm{Trans}^{+}$strains could take either route while transmigrating non-invasive $C$. jejuni strains $\left(\right.$ Inv $^{-} /$Trans $^{+}$) would be limited to the paracellular pathway. Bras and Ketley [49] described 6 C. jejuni isolates exhibiting various phenotypes in the Caco-2 infection model including $\mathrm{Inv}^{+} / \mathrm{Trans}^{+} \mathrm{Inv}^{+} / \mathrm{Trans}^{-}$and $\mathrm{Inv}^{-} / \mathrm{Trans}^{+}$strains, respectively. This study demonstrates that at least some Inv $/$ Trans $^{+}$ C. jejuni strains are to abound, which should travel exclusively by the paracellular route. In addition, the study shows that $\mathrm{Inv}^{+} / \mathrm{Trans}^{-}$strains exist. This means that invasive $C$. jejuni strains do not necessarily exit polarised epithelial cells at the basal membrane to complete the transmigration step, but obviously stay within the intracellular environment. In another study, transcytosis across polarized Caco- 2 monolayers was seen in 18 of the 21 colitis-associated $C$. jejuni strains, compared with only 11 of the 23 isolates from noninflammatory diarrhoea [36]. Interestingly, 6 strains from the latter group had the Inv $/$ Trans $^{+}$phenotype; again in such cases transcytosis can be unambiguously attributed to a paracellular passage [36]. Harvey and co-workers [38] compared $10 \mathrm{C}$. jejuni wild-type isolates and showed that they differ by at least 10 -fold in invasiveness and transmigration across Caco-2 cells. C. jejuni transmigration did not quantitatively correlate with the intracellular invasiveness of these isolates and a similar repertoire of strains including $\mathrm{Inv}^{+} /$

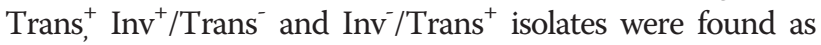
described above. Taken together, these data suggest that different phenotypic wild-type $C$. jejuni isolates exist in nature and that bacterial transmigration capabilities may correlate with colitis disease outcome. However, more studies are certainly necessary to substantiate this hypothesis.

\section{Transepithelial electrical resistance during $C$. jejuni transmigration: changed or unchanged?}

A well-established technique to confirm the presence of tight cell monolayers with proper TJs and to monitor changes in cell permeability during infection is measuring the transepithelial electrical resistance (TER) with electrodes [83]. For this purpose, polarized cell lines are commonly seeded and differentiated for up to 2-3 weeks in transwell chambers and TER values are followed over time and during the course of infection. However, in a few studies the cells were grown just for about 1 week or the growth period and TER values were not provided (Table 2). A common opinion is that bacterial transmigration by the paracellular route or toxic effects by the bacteria lead to disruption of $\mathrm{TJ}$ and $\mathrm{AJ}$ junctional complexes, consequently TER should drop, thus increasing cell monolayer permeability. Interestingly, while infection with Listeria, Shigella, Neisseria and Salmonella reduced TER substantially over time, infection with the C. jejuni $\mathrm{Inv}^{+} /$Trans $^{+}$strains 81-176, F38011 und NCTC11168 did not influence TER significantly $[44,45]$. Many other transmigration studies determined and followed TER during the course of $C$. jejuni infection $[38,40,43,49,50,84,85]$. In most of these reports, $C$. jejuni traversed the polarised cell monolayers without any apparent damage to the host cells. Commonly, within 4-8 h almost no difference was observed in the morphologic appearance of host cells and TER values of $C$. jejuni-infected versus non-infected monolayers $[37,38,40,44,50,84,85]$. Interestingly, both $C$. jejuni $\mathrm{Inv}^{+} / \mathrm{Trans}^{+}$and Inv $/$Trans $^{+}$strains traversed the Caco-2 cell monolayer without causing apparent cell damage as judged by TER [49]. This inability to measure TJ disruption led many researchers to hypothesize that $C$. jejuni cannot pass the epithelial barrier by the paracellular route, at least not at early times of infection $[38,43,49,84,85]$. In prolonged studies, some groups observed no TER changes even after $48 \mathrm{~h}$ of infection with $C$. jejuni [84], while others saw TER remaining unchanged until $24 \mathrm{~h}$ followed by a drop of TER either after $24 \mathrm{~h}$ [49] or $48 \mathrm{~h}$ [43]. The drop of TER in vitro indicates that opening of TJs and AJs by C. jejuni associated with massive cell monolayer disruption can occur at late times of infection. Immunofluorescence microscopy of polarized T84 monolayers infected for $24 \mathrm{~h}$ with $C$. jejuni revealed a redistribution of the $\mathrm{TJ}$ transmembrane protein occludin from an intercellular to an intracellular location associated with a change in phosphorylation [41]. Host cell degeneration is consistent with the tissue damage and inflammation found in many cases of campylobacteriosis in vivo (Table 1 ).

\section{Electron microscopy reveals $C$. jejuni within and between neighboring epithelial cells}

Proper monolayers and junction formation in polarized cells when grown in transwells have been confirmed by scanning electron microscopy (SEM) or transmission electron microscopy (TEM), which also illustrated the presence of microvilli and well-defined brush borders at the apical cell surface $[39,40]$. In addition, immunofluorescence 
microscopy staining for JAM (a TJ marker) and E-cadherin (an AJ marker) was used to verify intact cell-to-cell junctions [44]. SEM and TEM studies were then applied to investigate the interaction of $C$. jejuni with polarized Caco- 2 cells. The efficiency of $C$. jejuni invasion of Caco-2 cells was 2- to 3-fold less as compared to non-polarised INT-407 cells [39]. Interestingly, only $11-17 \%$ of differentiated Caco-2 cells were found to contain bound or internalized C. jejuni, and even smaller percentage of Caco-2 cells contained 5-20 internalized bacteria per cell after $2 \mathrm{~h}$ of infection [39]. Furthermore, SEM and TEM demonstrated that $C$. jejuni were present extracellularly between two neighboring Caco- 2 cells as well as intracellularly $[39,40]$. Similar TEM observations have been obtained by some other researchers showing intracellular $C$. jejuni, which remain tightly surrounded by a host-derived membrane (the Campylobacter vacuole) after invasion into epithelial cells in vitro and in vivo [22,25,39,40,43,50,86]. It was therefore suggested that $C$. jejuni could translocate across polarized cell monolayers by passing through single cells (Figure 3A) and/or between two neighboring cells (Figure 3B).

\section{Bacterial and host factors involved in C. jejuni transmigration across polarised cells}

The process of $C$. jejuni transmigration across polarised intestinal cells is not fully understood because only a handful putative bacterial and host factors have been reported yet. The application of pharmacological inhibitors has indicated that the activity of phosphoinositid-3-kinase is necessary for C. jejuni transcytosis [43]. The role of membrane lipid rafts was assessed by pharmacological depletion of cholesterol and caveolin co-localization using immunofluorescence microscopy [85]. In addition, it was shown that $C$. jejuni transmigration was enhanced by adding interferon-gamma, probably because of its TER-reducing capabilities during inflammation [87]. Many other studies have shown that inactivation of flagellar genes in C. jejuni resulted in a colonization-negative phenotype in various animal models $[2,8,9]$. Early studies using polarized Caco- 2 cells and various flagellar and motility mutants indicated that either C. jejuni motility or the flagellin gene products or both appear to be essential for translocation across the polarized monolayer in vitro [37]. For example, C. jejuni mutants GRK5 and GRK7 (FlaA FlaB Mot') and GRK17 (FlaA FlaB ${ }^{+}$Mot $^{-}$) were unable to cross the Caco-2 cellular barrier as compared to $\mathrm{Mot}^{+}$control strains [37]. Another flagellin knockout $(\triangle f l a A / B)$ and $\Delta$ flgF mutants with Mot $^{-}$phenotype were also diminished in passing polarised T84 or MKN-28 cells, respectively $[43,44,85]$. In addition, the wild-type strain NCTC12189, a C. jejuni variant that has reduced motility $\left(\mathrm{Mot}^{-/+}\right)$despite retaining intact flagella, was unable to colonise the intestinal tract of infant mice [88] and elicited no histological changes in the rabbit intestinal mucosa nor $C$. jejuni-positive blood culture [26]. It was therefore proposed that flagella and associated motility are the driving forces for colonization, invasion and transmigration properties of $C$. jejuni.

The flagellum does not only have a distinct function in bacterial motility and cell binding, but also acts as a type III secretion system (T3SS) for the delivery of Cia (Campylobacter invasion antigens) proteins into the extracellular space or into the host cell [89-93]. The first described Cia protein member is $\mathrm{CiaB}$ [89]. The $\mathrm{CiaB}$ protein was reported to be translocated into the cytoplasm of host cells, suggesting that it is a T3SS effector molecule facilitating invasion [89]. CiaB expression was also shown to be crucial for the secretion of at least eight other Cia proteins, ranging in size from 12.8 to $108 \mathrm{kDa}$, that were induced upon host cell contact or by the presence of calf serum [94]. However, the exact function of $\mathrm{CiaB}$ is not yet clear. Interestingly, the invasion-defective $\Delta c i a B$ mutant was able to transmigrate across polarised T84 cells like wild-type bacteria suggesting that apical cell invasion is not necessary for $C$. jejuni transmigration, thus favoring the paracellular route [42]. Further arguments for the paracellular route came from competition experiments with soluble fibronectin and observations that the $\Delta c a d F$ mutant (deficient in fibronectin-binding and invasion) also transmigrated as effectively as wild-type C. jejuni strain F38011 [42]. This report is counteracted by another publication showing that a LOS-deficient $\Delta$ cstII mutant in C. jejuni strain GB11 exhibited a strong deficiency of invasion and transmigration as determined by GPA, immunofluorescence microscopy and transwell assays, thus favoring a transcellular route [59]. Unfortunately, in the latter two studies two different cell systems were used and TER was not followed over time (Table 2). Thus, differences in these observations are not yet clear, but could be explained by strain-specific properties.

\section{Role of serine protease HtrA and E-cadherin cleavage in C. jejuni transmigration}

Recently, another factor was identified to be a novel virulence determinant in C. jejuni, the serine protease HtrA (high temperature resistant protein A) [69]. Deletion of the htrA gene in two strains resulted in strong deficiency of $C$. jejuni to travel across polarised MKN-28 cells [44,45]. This mutant was not affected with regard to motility and flagella production, suggesting that bacterial motility per $s e$ is not sufficient for C. jejuni transmigration [44], but htrA-mediated cell binding maybe involved [69]. Another important new discovery was that HtrA can be secreted into the cell culture supernatant by $C$. jejuni, although this class of proteases has well-known functions as chaperone and protein quality controllers in the periplasm of $E$. coli $[44,45]$. Secretion of HtrA by C. jejuni was enhanced during host cell contact or in the presence of calf serum, but was 


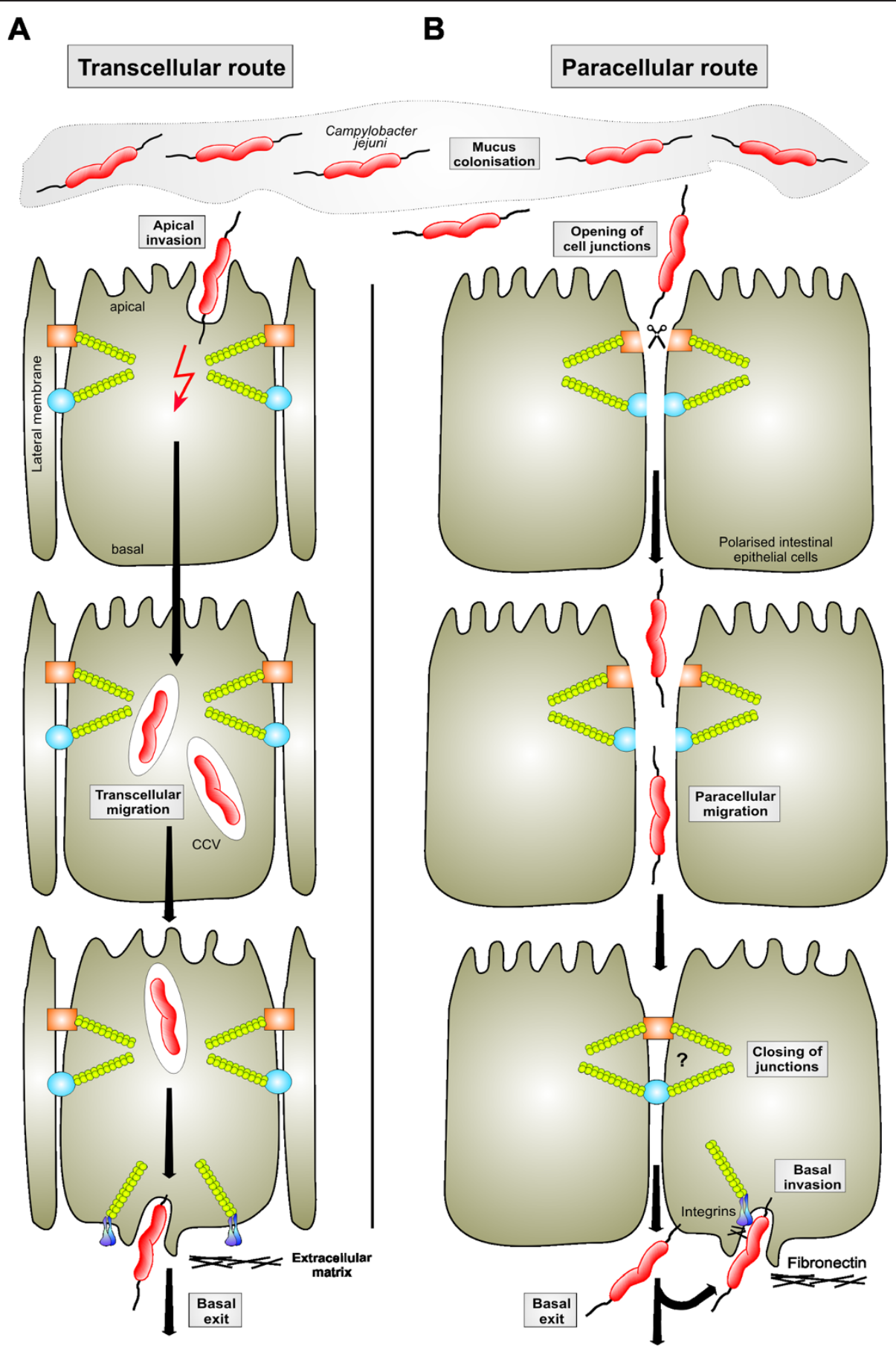

Figure 3 Models for transepithelial migration across polarised epithelial cells by $\boldsymbol{C}$. jejuni. Simplified schematic diagram depicting cell junctions and two considered routes of bacterial travel across a polarized epithelium. The apical surface of the epithelial monolayer faces the external environment to the gut and forms the first barrier for C. jejuni invasion. Cell junctions important for the structural stability of a polarized epithelium include the tight junctions, adherens junctions, and matrix receptors as indicated. Various routes for C. jejuni transmigration have been proposed. (A) The transcellular route is characterized by pathogens crossing the epithelial barrier through entering the cells at the apical surface and exiting the cells at the basal membrane. (B) The paracellular route is taken by the bacteria entering the epithelium between two neighboring cells, thus crossing cells through the tight and adherens junctions. Opening of the cell-to-cell junctions maybe a temporal process and potentially close again after C. jejuni have passed. Basal exiting C. jejuni express the adhesin CadF which can bind to the fibronectin $\rightarrow$ integrin complex utilized for invasion from the bottom of epithelial cells. 
independent of the flagellar T3SS [95]. Infection studies and protease assays showed that HtrA cleaves the major AJ protein E-cadherin on epithelial cells and the recombinant protein in vitro $[44,45]$. Interestingly, E-cadherin cleavage has also been found for the HtrA proteins of other enteric pathogens including Shigella, Helicobacter and EPEC, but not for the urogenital pathogen Neisseria [45]. HtrA-mediated E-cadherin cleavage led to the disruption of AJs allowing $H$. pylori or $C$. jejuni to enter the intercellular space. In further studies, the HtrA ortholog in H. pylori has also been shown to cleave another protein, fibronectin, but $C$. jejuni HtrA has obviously lost this activity over fibronectin during evolution [44,96]. The molecular reason for this observation is unknown, however, it is in agreement with the concept that fibronectin is a major basolateral host factor necessary for $C$. jejuni binding to integrins and host cell invasion, at least during infection of non-polarised cells [42,71,72,97,98].

Deletion of $h t r A$ or substitution of $h t r A$ with a proteasedeficient S197A point mutant in the bacteria resulted in severe defects for E-cadherin cleavage and C. jejuni transcytosis through MKN-28 cells [44,45]. Thus, cleavage of host junctional proteins like E-cadherin (and probably other yet unidentified host factors) by secreted HtrA could explain how $C$. jejuni may transmigrate intercellularly between neighboring cells using the paracellular route. Interestingly, in a time course of $C$. jejuni infection the total amount of cell-associated E-cadherin dropped to some extent, but did not lead to a complete cleavage, not even in $8 \mathrm{~h}$ infections [44]. It was therefore proposed that cleavage of E-cadherin by HtrA could be strictly controlled, in a temporal and spatial manner, during infection. Such a localized action of the bacterial protease could possibly be achieved by restricting secretion of HtrA to the time point, when the bacteria attach to cell-cell adhesion sites [44]. As the host cell translation machinery continuously produces large amounts of E-cadherin, the host cells can quickly substitute cleaved proteins. This hypothesis could also explain why no significant reduction in TER was observed during infection with $C$. jejuni and suggests that these bacteria could somehow open and close the "door" between two neighboring cells [44]. Such a mechanism could be analogous to transendothelial migration of neutrophils, which transmigrate effectively from the bloodstream to the site of infection and do not cause any damage to the endothelial cells [99]. If our hypothesis turns out to be true, it may represent a clever novel infection strategy for transmigration of pathogens such as C. jejuni across polarised host epithelial cells.

\section{Translocation studies of other Campylobacter species}

Studies on the epithelial transmigration of Campylobacters other than $C$. jejuni are rare in the literature, with only a few reports on $C$. fetus, $C$. rectus and $C$. coli. In a first study, the ability to translocate across epithelial barriers has been investigated during infection with C.fetus, a recognized pathogen of cattle, sheep and humans [100]. Using cultured Caco-2 cells, C. fetus was found to translocate efficiently within $24 \mathrm{~h}$ without altering TER, similar to C. jejuni as discussed above. C. fetus was also observed to invade and subsequently egress from Caco- 2 cells as shown in a modified GPA procedure and this occurred independently of C. fetus S layer expression [100]. SEM and TEM studies revealed the presence of $C$. fetus both at apical and basal surfaces as well as in intracellular locations, but not in the paracellular space. Pharmacological inhibitor studies demonstrated the requirement of a functional tubulin cytoskeleton, and together with the TEM data support a transcellular mechanism for C. fetus transmigration across Caco-2 monolayers [100]. Thus, the ability to invade and subsequently egress may contribute to establishing C. fetus infections in various hosts and can explain bacterial recovery from extraintestinal sites [100]. In a second report, C. rectus, a periodontal pathogen associated with human fetal exposure and adverse pregnancy outcomes including preterm delivery, was investigated [101]. Infection experiments in pregnant $\mathrm{BALB} / \mathrm{c}$ mice have demonstrated that $C$. rectus can translocate from a distant site of infection to the placenta where it can induce fetal growth restriction and impairs placental development [101]. Infection with C. rectus was detected in $63 \%$ of placentas after two weeks and significantly decreased fetoplacental weight. In invasion assays, C. rectus was able to effectively invade human trophoblasts in vitro (but not trophoblasts of murine origin), and showed a trend for higher invasiveness as compared to $C$. jejuni. Interestingly, $C$. rectus infection significantly upregulated IL- 6 and TNF- $\alpha$ levels in a dose-dependent manner in human trophoblasts, but not in murine cells, suggesting a correlation between invasion and cytokine activation [101]. It was proposed that the invasive trait of C. rectus in human trophoblasts may play a role in facilitating bacterial translocation and placental inflammation during early gestation [101]. A third report investigated C. coli, which is the dominant Campylobacter species commonly found in pigs [102]. An experimental trial was conducted to evaluate the colonisation and translocation ability of the porcine $C$. coli strain 5981 in weaned pigs over 28 days. Excretion of C. coli 5981 was seen for all piglets 7 days after inoculation and highest counts were detectable on day 10 [102]. Post-mortem, of luminal C. coli was observed for gut tissues of the small intestine and for the gut associated lymphatic tissues, such as jejunal mesenteric lymph nodes and tonsils as well as for spleen and gall bladder. In conclusion, this trial indicates that C. coli exhibit translocation and invasion capabilities in pigs making it a useful model system to study colonisation and pathogenicity of this pathogen [102]. 


\section{Concluding remarks}

Different mechanisms are used by various enteropathogens to transmigrate across the host intestinal epithelium, including transcytosis through specialized M cells, phagocytosis by interepithelial leukocytes or transcytosis of enterocytes $[35,81,82]$. C. jejuni is a predominant zoonotic pathogen causing enterocolitis in humans worldwide. However, despite the high prevalence of $C$. jejuni induced disease and research progress made in recent years, our knowledge is still relatively limited as compared to other invasive pathogens such as Salmonella, Listeria or Shigella. A series of studies on human biopsies and animal infection experiments have demonstrated that $C$. jejuni is able to cross the intestinal epithelial barrier and enter underlying tissues, bloodstream and even other organs (Table 1). However, the mechanism of C. jejuni translocation is controverse and not well understood. There is only one report that $\mathrm{M}$ cells in the Peyer's patches may facilitate transport of C. jejuni from the intestine in rabbits [103]. From in vitro studies it seems clear that $C$. jejuni transmigration across polarised cultured cells requires de novo protein synthesis and depends on functional flagella. Unfortunately, there is no consensus on the transepithelial route followed by $C$. jejuni, both the transcellular and paracellular routes have been described (Table 2). If apical binding of $C$. jejuni to epithelial cells is a prerequisite for subsequent invasion and transcellular migration is also unclear. There is rapid increase in reports on putative bacterial adhesion factors - we have now a list of more than 20 bacterial factors with proposed role in binding and subsequent invasion [11]. In contrast, there is a large gap in our knowledge on corresponding host cell receptors. Thus, there is an urgent need for identifying and characterizing host receptors which can be attributed to certain bacterial factors. The only receptor pathway intensively studied and verified by various independent research groups is the $\mathrm{CadF} \rightarrow$ fibronectin $\rightarrow$ integrin signaling cascade $[42,71,72,97,98,104]$. These studies have presented high resolution SEM pictures of various invading C. jejuni strains (showing details of the invagination process) in multiple non-polarised cell types [71,97,98], but corresponding qualitative and quantitative SEM data for a set of $C$. jejuni strains invading polarised cells from apical or basal membranes are currently not available. Alternative possibilities include the involvement of ganglioside-like LOS in apical invasion, thus favoring a transcellular route [59], but this model is in contrast to the paracellular model for HtrA-mediated opening of AJs and basal invasion as triggered by the $\mathrm{CadF} \rightarrow$ fibronectin $\rightarrow$ integrin complex $[44,45]$. How C. jejuni can open the TJs after longer coincubation times is yet unclear. Several studies exist that could support the apical invasion model, but can C. jejuni also enter host cells from basal surfaces? Basal engulfment and entry of $C$. jejuni into non-polarised Chang or polarised
Caco- 2 cells has been demonstrated by TEM and immunofluorescence microscopy, and this process has been called subvasion $[79,105]$. However, if paracellular transmigration is a prerequisite for subvasion in polarised cells is not yet clear. Furthermore, it is also unclear how the T3SSdependent injection of certain Cia proteins fits in any of the above models. Thus, more studies are clearly required to unravel the sequence of events that allow C. jejuni strains to travel across polarised intestinal epithelial cells, either by a transcellular or paracellular pathway or a mix of both. It should be also considered that individual $C$. jejuni strains might switch from one to the other mode under specific culturing or infection conditions. Finally, besides the commonly applied transwell system, a vertical diffusion chamber model system has been recently described, which creates microaerobic conditions at the apical surface and aerobic conditions at the basolateral surface of cultured intestinal epithelial cells, thus producing an in vitro system that probably closely mimics in vivo conditions of the human intestine [106]. The use of this vertical diffusion chamber for studying the interactions of $C$. jejuni with intestinal epithelial cells demonstrated the importance of performing such experiments under conditions that converge to the in vivo situation and will allow novel insights into $C$. jejuni pathogenic mechanisms [106]. In addition, it should be noted that most of the cell lines used for in vitro studies are already transformed because they originate from cancer patients. A possible alternative option came from recent studies demonstrating that single Lgr5 (the receptor for the Wnt-agonistic R-spondins)-positive stem cells isolated from the intestine can grow in culture into complex epithelial organoid structures, called miniguts, which retain their original organ identity [107-109]. This important example of self-organization could be used for stem cell research and regenerative medicine, but also disease modeling of infections with enteric pathogens including Campylobacter. It therefore appears that transmigration of $C$. jejuni and that of many other Campylobacter species will continue to be a fascinating and rewarding research subject in the future.

\section{Competing interests \\ The authors declare that they have no competing interests.}

\section{Authors' contributions}

SB performed the data collection and wrote the text. MB designed Table 1 and SW designed Table 2. NT was drawing the figures and wrote the figure legends. All authors discussed, read and approved the text including the final manuscript.

\section{Acknowledgements}

The work of SB is supported through a DFG grant (project B10 of CRC-796).

\section{Author details}

'Department of Biology, Institute for Microbiology, Friedrich Alexander University Erlangen/Nuremberg, Staudtstr. 5, D-91058, Erlangen, Germany. ${ }^{2}$ Department of Molecular Biology, Division of Microbiology, Paris-Lodron University of Salzburg, Billroth Str. 11, A-5020, Salzburg, Austria. 
Received: 4 August 2013 Accepted: 18 September 2013

Published: 30 September 2013

\section{References}

1. Friedman CR, Neimann J, Wegener HC, Tauxe RV: Epidemiology of Campylobacter jejuni infections in the United States and other industrialized nations. In Campylobacter. Edited by Nachamkin I, Blaser MJ. Washington, DC: ASM Press; 2000:121-138.

2. Young KT, Davis LM, Dirita VJ: Campylobacter jejuni: molecular biology and pathogenesis. Nature Rev Microbiol 2007, 5:665-679.

3. van Putten JP, van Alphen LB, Wosten MM, de Zoete MR: Molecular mechanisms of Campylobacter infection. Curr Top Microbiol Immunol 2009, 337:197-229.

4. Dasti Jl, Tareen AM, Lugert R, Zautner AE, Gross U: Campylobacter jejuni: a brief overview on pathogenicity-associated factors and disease-mediating mechanisms. Int J Med Microbiol 2010, 300:205-211.

5. Oyarzabal OA, Backert S: Microbial Food Safety. New York: Springer; 2011. ISBN 978-1-4614-1176-5.

6. Nachamkin I, Szymanski CM, Blaser MJ: Campylobacter. Washington, DC: ASM Press; 2008

7. Zilbauer M, Dorrell N, Wren BW, Bajaj-Elliott M: Campylobacter jejuni-mediated disease pathogenesis: an update. Trans R Soc Trop Med Hyg 2008, 102:123-129.

8. Szymanski CM, King M, Haardt M, Armstrong GD: Campylobacter jejuni motility and invasion of Caco-2 cells. Infect Immun 1995, 63:4295-4300.

9. Hendrixson DR, DiRita VJ: Identification of Campylobacter jejuni genes involved in commensal colonization of the chick gastrointestinal tract. Mol Microbiol 2004, 52:471-484

10. Janssen R, Krogfelt KA, Cawthraw SA, van Pelt W, Wagenaar JA, Owen RJ: Host-pathogen interactions in Campylobacter infections: the host perspective. Clin Microbiol Rev 2008, 21:505-518.

11. ÓCróinín T, Backert S: Host epithelial cell invasion by Campylobacter jejuni: trigger or zipper mechanism? Front Cell Infect Microbiol 2012, 2:25.

12. Wessler S, Backert S: Molecular mechanisms of epithelial-barrier disruption by Helicobacter pylori. Trends Microbiol 2008, 16:397-405.

13. Snoeck V, Goddeeris B, Cox E: The role of enterocytes in the intestinal barrier function and antigen uptake. Microbes Infect 2005, 7:997-1004.

14. Laukoetter MG, Nava $P$, Nusrat $A$ : Role of the intestinal barrier in inflammatory bowel disease. World J Gastroenterol 2008, 14:401-407.

15. Cavallaro U, Christofori $\mathrm{G}$ : Cell adhesion and signalling by cadherins and lg-CAMs in cancer. Nat Rev Cancer 2004, 4:118-132.

16. Hynes RO: Integrins: bidirectional, allosteric signaling machines. Cell 2002, 110:673-687.

17. Luo BH, Carman CV, Springer TA: Structural basis of integrin regulation and signaling. Annu Rev Immunol 2007, 25:619-647.

18. de Pereda JM, Ortega E, Alonso-García N, Gómez-Hernández M, Sonnenberg A: Advances and perspectives of the architecture of hemidesmosomes: lessons from structural biology. Cell Adh Migr 2009, 3:361-364.

19. Vogelmann R, Amieva MR, Falkow S, Nelson WJ: Breaking into the epithelial apical-junctional complex - news from pathogen hackers. Curr Opin Cell Biol 2004, 16:86-93.

20. Fasano A, Nataro JP: Intestinal epithelial tight junctions as targets fo enteric bacteria-derived toxins. Adv Drug Deliv Rev 2004, 56:795-807.

21. Backert S, König W: Interplay of bacterial toxins with host defence: molecular mechanisms of immunomodulatory signalling. Int J Med Microbiol 2005, 295:519-530.

22. van Spreeuwel JP, Duursma GC, Meijer CJ, Bax R, Rosekrans PC, Lindeman J: Campylobacter colitis: histological immunohistochemical and ultrastructural findings. Gut 1985, 26:945-951

23. Russell RG, O'Donnoghue M, Blake DC Jr, Zulty J, DeTolla LJ: Early colonic damage and invasion of Campylobacter jejuni in experimentally challenged infant Macaca mulatta. J Infect Dis 1993, 168:210-215.

24. Humphrey CD, Montag DM, Pittman FE: Morphologic observations of experimental Campylobacter jejuni infection in the hamster intestinal tract. Am J Pathol 1986, 122:152-159.

25. Babakhani FK, Bradley GA, Joens LA: Newborn piglet model for campylobacteriosis. Infect Immun 1993, 61:3466-3475.

26. Everest PH, Goossens H, Sibbons P, Lloyd DR, Knutton S, Leece R, Ketley JM, Williams PH: Pathological changes in the rabbit ileal loop model caused by Campylobacter jejuni from human colitis. J Med Microbiol 1993, 38:316-321.

27. Nemelka KW, Brown AW, Wallace SM, Jones E, Asher LV, Pattarini D, Applebee $L$, Gilliland TC Jr, Guerry P, Baqar S: Immune response to and histopathology of Campylobacter jejuni infection in ferrets (Mustela putorius furo). Comp Med 2009, 59:363-371.

28. Vucković D, Abram M, Dorić M: Primary Campylobacter jejuni infection in different mice strains. Microb Pathog 1998, 24:263-268.

29. Watson RO, Novik V, Hofreuter D, Lara-Tejero M, Galan JE: A MyD88-deficient mouse model reveals a role for Nramp1 in Campylobacter jejuni infection. Infect Immun 2007, 75:1994-2003.

30. Lamb-Rosteski JM, Kalischuk LD, Inglis GD, Buret AG: Epidermal growth factor inhibits Campylobacter jejuni-induced claudin-4 disruption, loss of epithelial barrier function, and Escherichia coli translocation. Infect Immun 2008, 76:3390-3398.

31. Welkos SL: Experimental gastroenteritis in newly-hatched chicks infected with Campylobacter jejuni. J Med Microbiol 1984, 18:233-248.

32. Beery JT, Hugdahl MB, Doyle MP: Colonization of gastrointestinal tracts of chicks by Campylobacter jejuni. Appl Environ Microbiol 1988, 54:2365-2370.

33. Lee A, O'Rourke JL, Barrington PJ, Trust TJ: Mucus colonization as a determinant of pathogenicity in intestinal infection by Campylobacter jejuni: a mouse cecal model. Infect Immun 1986, 51:536-546.

34. Kazmierczak Bl, Mostov K, Engel JN: Interaction of bacterial pathogens with polarized epithelium. Annu Rev Microbiol 2001, 55:407-435.

35. Sears CL: Molecular physiology and pathophysiology of tight junctions $\mathrm{V}$. assault of the tight junction by enteric pathogens. Am J Physiol Gastrointest Liver Physiol 2000, 279:G1129-G1134.

36. Everest PH, Goossens H, Butzler JP, Lloyd D, Knutton S, Ketley JM, Williams $\mathrm{PH}$ : Differentiated Caco-2 cells as a model for enteric invasion by Campylobacter jejuni and C. coli. J Med Microbiol 1992, 37:319-325.

37. Grant CCR, Konkel ME, Cieplak W Jr, Tompkins LS: Role of flagella in adherence, internalization, and translocation of Campylobacter jejuni in nonpolarized and polarized epithelial cell cultures. Infect Immun 1993, 61:1764-1771.

38. Harvey P, Battle T, Leach S: Different invasion phenotypes of Campylobacter isolates in Caco-2 cell monolayers. J Med Microbiol 1999, 48:461-469.

39. Hu L, Tall BD, Curtis SK, Kopecko DJ: Enhanced microscopic definition of Campylobacter jejuni 81-176 adherence to, invasion of, translocation across, and exocytosis from polarized human intestinal Caco-2 cells. Infect Immun 2008, 76:5294-5304

40. Konkel ME, Mead DJ, Hayes SF, Cieplak W Jr: Translocation of Campylobacter jejuni across Human Polarized Epithelial Cell Monolayer Cultures. J Infect Dis 1992, 166:308-315.

41. Chen ML, Ge Z, Fox JG, Schauer DB: Disruption of tight junctions and induction of proinflammatory cytokine responses in colonic epithelial cells by Campylobacter jejuni. Infect Immun 2006, 74:6581-6589.

42. Monteville MR, Konkel ME: Fibronectin-facilitated invasion of T84 eukaryotic cells by Campylobacter jejuni occurs preferentially at the basolateral cell surface. Infect Immu 2002, 70:6665-6671.

43. Wine $\mathrm{E}$, Chan VL, Sherman PM: Campylobacter jejuni mediated disruption of polarized epithelial monolayers is cell-type specific, time dependent, and correlates with bacterial invasion. Pediatr Res 2008, 64:599-604.

44. Boehm M, Hoy B, Rohde M, Tegtmeyer N, Baek KT, Oyarzabal OA, Brondsted L, Wessler S, Backert S: Rapid paracellular transmigration of Campylobacter jejuni across polarized epithelial cells without affecting TER: role of proteolytic-active HtrA cleaving E-cadherin but not fibronectin. Gut Pathog 2012, 4:3.

45. Hoy B, Geppert T, Boehm M, Reisen F, Plattner P, Gadermaier G, Sewald N, Ferreira F, Briza P, Schneider G, Backert S, Wessler S: Distinct roles of secreted HtrA proteases from Gram-negative pathogens in cleaving the junctional protein and tumor suppressor E-cadherin. J Biol Chem 2012, 287:10115-10120

46. Alemka A, Clyne M, Shanahan F, Tompkins T, Corcionivoschi N, Bourke B: Probiotic colonization of the adherent mucus layer of HT29MTXE12 cells attenuates Campylobacter jejuni virulence properties. Infect Immun 2010, 78:2812-2822

47. Dolan B, Naughton J, Tegtmeyer N, May FE, Clyne M: The interaction of Helicobacter pylori with the adherent mucus gel layer secreted by polarized HT29-MTX-E12 cells. PLOS One 2012, 7:e47300.

48. Konkel ME, Corwin MD, Joens LA, Cieplak W: Factors that influence the interaction of Campylobacter jejuni with cultured mammalian cells. J Med Microbiol 1992, 37:30-37.

49. Brás AM, Ketley JM: Transcellular translocation of Campylobacter jejuni across human polarised epithelial monolayers. FEMS Microbiol Lett 1999, 179:209-215.

50. Beltinger J, del Buono J, Skelly MM, Thornley J, Spiller RC, Stack WA, Hawkey $\mathrm{CJ}$ : Disruption of colonic barrier function and induction of mediator 
release by strains of Campylobacter jejuni that invade epithelial cells. World J Gastroenterol 2008, 14:7345-7352.

51. Backert S, Hofreuter D: Molecular methods to investigate adhesion, transmigration, invasion and intracellular survival of the foodborne pathogen Campylobacter jejuni. J Microbiol Meth 2013, 95:8-23.

52. McSweegan E, Walker RL: Identification and characterization of two Campylobacter jejuni adhesins for cellular and mucous substrates. Infect Immun 1986, 53:141-148,

53. Yao R, Burr DH, Doig P, Trust TJ, Niu H, Guerry P: Isolation of motile and non-motile insertional mutants of Campylobacter jejuni: the role of motility in adherence and invasion of eukaryotic cells. Mol Microbiol 1994, 14:883-893.

54. Yao R, Burr DH, Guerry P: CheY-mediated modulation of Campylobacter jejuni virulence. Mol Microbiol 1997, 23:1021-1031.

55. Wösten MM, Wagenaar JA, van Putten JP: The FlgS/FlgR two-component signal transduction system regulates the fla regulon in Campylobacter jejuni. J Biol Chem 2004, 279:16214-16222.

56. Mertins $\mathrm{S}$, Allan BJ, Townsend HG, Köster W, Potter AA: Role of motAB in adherence and internalization in polarized Caco- 2 cells and in cecal colonization of Campylobacter jejuni. Avian Dis 2013, 57:116-122.

57. Guerry P, Ewing CP, Schirm M, Lorenzo M, Kelly J, Pattarini D, Majam G, Thibault P, Logan S: Changes in flagellin glycosylation affect Campylobacter autoagglutination and virulence. Mol Microbiol 2006, 60:299-311.

58. Fry BN, Feng S, Chen YY, Newell DG, Coloe PJ, Korolik V: The galE gene of Campylobacter jejuni is involved in lipopolysaccharide synthesis and virulence. Infect Immun 2000, 68:2594-2601.

59. Louwen R, Nieuwenhuis EE, van Marrewijk L, Horst-Kreft D, de Ruiter L, Heikema AP, van Wamel WJ, Wagenaar JA, Endtz HP, Samsom J, van Baarlen P, Akhmanova A, van Belkum A: Campylobacter jejuni translocation across intestinal epithelial cells is facilitated by ganglioside-like lipooligosaccharide structures. Infect Immun 2012, 80:3307-3318.

60. Szymanski CM, Burr DH, Guerry P: Campylobacter protein glycosylation affects host cell interactions. Infect Immun 2002, 70:2242-2244.

61. Bacon DJ, Szymanski CM, Burr DH, Silver RP, Alm RA, Guerry P: A phase-variable capsule is involved in virulence of Campylobacter jejuni 81-176. Mol Microbiol 2001, 40:769-777.

62. Bachtiar BM, Coloe PJ, Fry BN: Knockout mutagenesis of the kpsE gene of Campylobacter jejuni 81116 and its involvement in bacterium host interactions. FEMS Immunol Med Microbiol 2007, 49:149-154.

63. Ashgar SS, Oldfield NJ, Woolridge KG, Jones MA, Irving GJ, Turner DP, Ala'Aldeen DA: CapA, an autotransporter protein of Campylobacter jejuni mediates association with human epithelial cells and colonization of the chicken gut. J Bacteriol 2007, 189:1856-1865.

64. Fauchere JL, Kervella M, Rosenau A, Mohanna K, Veron M: Adhesion to HeLa cells of Campylobacter jejuni and C. coli outer membrane components. Res Microbiol 1989, 140:379-392.

65. Pei Z, Burucoa C, Grignon B, Baqar S, Huang XZ, Kopecko DJ, Bourgeois AL, Fauchere $J$ L, Blaser MJ: Mutation in the peb1A locus of Campylobacter jejuni reduces interactions with epithelial cells and intestinal colonization of mice. Infect Immun 1998, 66:938-943.

66. Kervella M, Pages JM, Pei Z, Grollier G, Blaser MJ, Fauchere JL: Isolation and characterization of two Campylobacter glycine-extracted proteins that bind to HeLa cell membranes. Infect Immun 1993, 61:3440-3448.

67. Asakura H, Yamasaki M, Yamamoto S, Igimi S: Deletion of peb4 gene impairs cell adhesion and biofilm formation in Campylobacter jejuni. FEMS Microbiol Lett 2007, 275:278-285.

68. Brøndsted L, Andersen MT, Parker M, Jørgensen $\mathrm{K}$, Ingmer H: The HtrA protease of Campylobacter jejuni is required for heat and oxygen tolerance and for optimal interaction with human epithelial cells. Appl Environ Microbiol 2007, 71:3205-3212.

69. Bæk KT, Vegge $C S$, Brøndsted L: HtrA chaperone activity contributes to host cell binding in Campylobacter jejuni. Gut Pathog 2011, 3:13.

70. Monteville MR, Yoon JE, Konkel ME: Maximal adherence and invasion of INT 407 cells by Campylobacter jejuni requires the CadF outer-membrane protein and microfilament reorganization. Microbiology 2003, 149:153-165.

71. Krause-Gruszczynska M, Rohde M, Hartig R, Genth H, Schmidt G, Keo T, Koenig W, Miller WG, Konkel ME, Backert S: Role of the small Rho GTPases Rac1 and Cdc42 in host cell invasion of Campylobacter jejuni. Cell Microbiol 2007, 9:2431-2444.

72. Krause-Gruszczynska M, Van Alphen LB, Oyarzabal OA, Alter T, Hänel I, Schliephake A, König W, Van Putten JP, Konkel ME, Backert S: Expression patterns and role of the CadF protein in Campylobacter jejuni and Campylobacter coli. FEMS Microbiol Lett 2007, 274:9-16.

73. Flanagan RC, Neal-McKinney JM, Dhillon AS, Miller WG, Konkel ME: Examination of Campylobacter jejuni putative adhesins leads to the identification of a new protein, designated FlpA, required for chicken colonization. Infect Immunol 2009, 77:2399-23407.

74. Javed MA, Grant AJ, Bagnall MC, Maskell DJ, Newell DG, Manning G Transposon mutagenesis in a hyper-invasive clinical isolate of Campylobacter jejuni reveals a number of genes with potential roles in invasion. Microbiology 2010, 156:1134-1143.

75. Tareen AM, Dasti II, Zautner AE, Gross U, Lugert R: Sulphite: cytochrome c oxidoreductase deficiency in Campylobacter jejuni reduces motility, host cell adherence and invasion. Microbiol 2011, 157:1776-1785.

76. Clark CG, Grant CC, Pollari F, Marshall B, Moses J, Tracz DM, Gilmour MW: Effects of the Campylobacter jejuni CJIE1 prophage homologs on adherence and invasion in culture, patient symptoms, and source of infection. BMC Microbiol 2012, 12:269. doi:10.1186/1471-2180-12-269.

77. Lertpiriyapong K, Gamazon ER, Feng Y, Park DS, Pang J, Botka G, Graffam ME, Ge Z, Fox JG: Campylobacter jejuni type VI secretion system: roles in adaptation to deoxycholic acid, host cell adherence, invasion, and in vivo colonization. PLoS One 2012, 7:e42842. doi:10.137. journal. pone.0042842. Epub 2012 Aug 27.

78. Jin S, Joe A, Lynett J, Hani EK, Sherman P, Chan VL: JlpA, a novel surface-exposed lipoprotein specific to Campylobacter jejuni, mediates adherence to host epithelial cells. Mol Microbiol 2001, 39:1225-1236.

79. van Alphen LB, Bleumink-Pluym NM, Rochat KD, van Balkom BW, Wösten MM, van Putten JP: Active migration into the subcellular space precedes Campylobacter jejuni invasion of epithelial cells. Cell Microbiol 2008, 10:53-66.

80. Novik V, Hofreuter D, Galán JE: Identification of Campylobacter jejuni genes involved in its interaction with epithelial cells. Infect Immun 2010, 78:3540-3553

81. Balkovetz DF, Katz J: Bacterial invasion by a paracellular route: divide and conquer. Microbes Infect 2003, 5:613-619.

82. Bencurova E, Mlynarcik P, Bhide M: An insight into the ligand-receptor interactions involved in the translocation of pathogens across blood-brain barrier. FEMS Immunol Med Microbiol 2011, 63:297-318.

83. Misfeldt DS, Hamamoto ST, Pitelka DR: Transepithelial transport in cell culture. Proc Natl Acad Sci USA 1976, 73:1212-1216.

84. Van Deun K, Pasmans F, Van Immerseel F, Ducatelle R, Haesebrouck F: Butyrate protects Caco-2 cells from Campylobacter jejuni invasion and translocation. Br J Nutr 2008, 100:480-484.

85. Kalischuk LD, Inglis GD, Buret AG: Campylobacter jejuni induces transcellular translocation of commensal bacteria via lipid rafts. Gut Pathog 2009, 1:2

86. De Melo MA, Gabbiani G, Pechere JC: Cellular events and intracellular survival of Campylobacter jejuni during infection of Hep-2 cells. Infect Immun 1989, 57:2214-2222.

87. Rees LE, Cogan TA, Dodson AL, Birchall MA, Bailey M, Humphrey TJ: Campylobacter and IFNgamma interact to cause a rapid loss of epithelial barrier integrity. Inflamm Bowel Dis 2008, 14:303-309.

88. Abimiku AG, Dolby JM, Borriello SP, Davies H: Protection against gastrointestinal colonization by Campylobacter jejuni in the infant mouse model. Microecol Ther 1989, 18:233-239.

89. Konkel ME, Kim BJ, Rivera-Amill V, Garvis SG: Identification of proteins required for the internalization of Campylobacter jejuni into cultured mammalian cells. Adv Exp Med Biol 1999, 473:215-224.

90. Young GM, Schmiel DH, Miller VL: A new pathway for the secretion of virulence factors by bacteria: the flagellar export apparatus functions as a protein secretion system. Proc Natl Acad Sci USA 1999, 96:6456-6461.

91. Guerry P: Campylobacter flagella: not just for motility. Trends Microbiol 2007, 15:456-461.

92. Christensen JE, Pacheco SA, Konkel ME: Identification of a Campylobacter jejuni-secreted protein required for maximal invasion of host cells. Mol Microbiol 2009, 73:650-662.

93. Neal-McKinney JM, Konkel ME: The Campylobacter jejuni CiaC virulence protein is secreted from the flagellum and delivered to the cytosol of host cells. Front Cell Infect Microbiol 2012, 2:31.

94. Rivera-Amill V, Konkel ME: Secretion of Campylobacter jejuni Cia proteins is contact dependent. Adv Exp Med Biol 1999, 473:225-229.

95. Boehm M, Haenel I, Hoy B, Brøndsted L, Smith TG, Hoover T, Wessler S, Tegtmeyer N: Extracellular secretion of protease HtrA from 
Campylobacter jejuni is highly efficient and independent of its protease activity and flagellum. Europ I Immunol Microbiol 2013, 3:163-173.

96. Hoy B, Löwer M, Weydig C, Carra G, Tegtmeyer N, Geppert T, Schröder P, Sewald N, Backert S, Schneider G, Wessler S: Helicobacter pylori HtrA is a new secreted virulence factor that cleaves E-cadherin to disrupt intercellular adhesion. EMBO Rep 2010, 11:798-804.

97. Krause-Gruszczynska M, Boehm M, Rohde M, Tegtmeyer N, Takahashi S, Buday L, Oyarzabal OA, Backert S: The signaling pathway of Campylobacter jejuni-induced Cdc42 activation: role of fibronectin, integrin beta1, tyrosine kinases and guanine exchange factor Vav2. Cell Commun Signal 2011, 9:32

98. Boehm M, Krause-Gruszczynska M, Rohde M, Tegtmeyer N, Takahashi S, Oyarzabal OA, Backert S: Major host factors involved in epithelial cell invasion of Campylobacter jejuni: role of fibronectin, integrin beta1, FAK, Tiam-1, DOCK180 in activating Rho GTPase Rac1. Front Cell Infect Microbiol 2011, 1:17.

99. Wagner JG, Roth RA: Neutrophil migration mechanisms, with an emphasis on the pulmonary vasculature. Pharmacol Rev 2000, 52:349-374.

100. Baker NT, Graham LL: Campylobacter fetus translocation across Caco-2 cell monolayers. Microb Pathog 2010, 49:260-272.

101. Arce RM, Diaz PI, Barros SP, Galloway P, Bobetsis Y, Threadgill D, Offenbacher S: Characterization of the invasive and inflammatory traits of oral Campylobacter rectus in a murine model of fetoplacental growth restriction and in trophoblast cultures. J Reprod Immunol 2010, 84:145-153.

102. Bratz K, Bücker R, Gölz G, Zakrzewski SS, Janczyk P, Nöckler K, Alter T: Experimental infection of weaned piglets with Campylobacter coli-excretion and translocation in a pig colonisation trial. Vet Microbiol 2013, 162:136-143.

103. Walker RI, Schmauder-Chock EA, Parker JL, Burr D: Selective association and transport of Campylobacter jejuni through M cells of rabbit Peyer's patches. Can J Microbiol 1988, 34:1142-1147.

104. Eucker TP, Konkel ME: The cooperative action of bacterial fibronectin-binding proteins and secreted proteins promote maximal Campylobacter jejuni invasion of host cells by stimulating membrane ruffling. Cell Microbiol 2012 14:226-238.

105. Bouwman LI, Niewold P, van Putten JP: Basolateral Invasion and Trafficking of Campylobacter jejuni in Polarized Epithelial Cells. PLoS One 2013, 8:e54759.

106. Mills DC, Gundogdu O, Elmi A, Bajaj-Elliott M, Taylor PW, Wren BW, Dorrell $\mathrm{N}$ : Increase in Campylobacter jejuni invasion of intestinal epithelial cells under low-oxygen coculture conditions that reflect the in vivo environment. Infect Immun 2012, 80:1690-1698.

107. Sato T, Clevers H: Growing self-organizing mini-guts from a single intestinal stem cell: mechanism and applications. Science 2013, 340:1 190-1194.

108. Guillot C, Lecuit T: Mechanics of epithelial tissue homeostasis and morphogenesis. Science 2013, 340:1185-1189.

109. Clevers $\mathrm{H}$ : The intestinal crypt, a prototype stem cell compartment. Cell 2013, 154:274-284.

doi:10.1186/1478-811X-11-72

Cite this article as: Backert et al:: Transmigration route of Campylobacter jejuni across polarized intestinal epithelial cells: paracellular, transcellular or both? Cell Communication and Signaling 2013 11:72.

\section{Submit your next manuscript to BioMed Central and take full advantage of:}

- Convenient online submission

- Thorough peer review

- No space constraints or color figure charges

- Immediate publication on acceptance

- Inclusion in PubMed, CAS, Scopus and Google Scholar

- Research which is freely available for redistribution

Submit your manuscript at www.biomedcentral.com/submit
C BiolMed Central 